\title{
Encuentros entre la India y Occidente en el mundo antiguo
}

\author{
M. a TeResa RoMÁn López *
}

\section{RESUMEN ABSTRACT}

Hay diversos testimonios sobre relaciones comerciales y culturales que, mucho antes de la caída de Babilonia y hasta el siglo vi de nuestra Era, tenían lugar entre el Próximo Oriente y Occidente, por un lado, y la India por otro. La expedición de Alejandro Magno en la India dio lugar no sólo a contactos militares, sino a debates filosófico-religiosos. Se halla una descripción casi completa de la flora en los autores griegos, y no es posible ignorar el arte grecobúdico que floreció después de la muerte de Alejandro en los reinos helénicos de la frontera. Está demostrado que misioneros budistas fueron enviados por el emperador Ashoka a Siria, Egipto, Macedonia, etc. En la época del Imperio romano las relaciones entre la India y el mundo occidental fueron muy frecuentes.
There are several testimonies about comercial and cultural relationships that, after the falling of Babilonia and until the VI century of our edge, were made between next Orient and Occident in one side, and India on the other side.

The expedition of Alexander the Great to India made, note only military relations but philosophie and religious debates. It has been found a mostly complete description of the Flora on the greek authors, and it's not posible to ignore the grecobudie art that bloomed after Alexander death at the Helenic Kingdoms on the border. It's proved that budist missioners were send by the Ashoka emperor to Siria, Egipt, Macedonie, etc. On the Roman Empire edge the relationships between India and the Occident world were so frecuent.

* Dpto. Filosofía y Filosofía Moral y Política. UNED. 


\section{CONTACTOS ENTRE LA INDIA Y GRECIA ANTES DE LA CONQUISTA DE ALEJANDRO MAGNO}

A todo el que se arriesgue a surcar el vasto y multicolor océano del pensamiento religioso indio puede que le sorprenda el hecho de que sólo al finalizar el siglo XVIII llegue al conocimiento de la vieja Europa la inmensa y compleja manifestación cultural del pueblo de la India.

No obstante, la India en mayor medida que cualquier otro pueblo de la tierra, en el período antiguo, en el medievo y en la edad moderna atraerá la atención de los amantes de la ciencia en Oriente ${ }^{1}$ y Occidente. Pueblos como los egipcios, los hebreos, los fenicios, los asirios, los medos y los persas conseguirán penetrar en las exuberantes tierras de la India, en busca de piedras preciosas, de especias y perfumes, convirtiéndolas en objetivo de ambiciosas conquistas y dejando señales profundas de sus incursiones en narraciones y leyendas, en los nombres de animales y objetos, en imágenes y en divinidades. Grecia, última en el tiempo y primera en ilustrar la vida social de los pueblos con quienes entra en contacto, no sólo deja testimonio de sus visitas y expediciones en monumentos, monedas e inscripciones, sino que transmite a las generaciones futuras informaciones redactadas por testigos presenciales, entreveradas frecuentemente por leyendas.

Si prescindimos de las vagas alusiones del poeta épico griego Homero (vivió hacia el 850 a.C.) en su Odisea, III, I, 22-24, donde la frase "etíopes orientales» quizá haga referencia a los habitantes indios, Europa debe sus primeros conocimientos acerca del subcontinente al historiador griego Heródoto (siglo $v$ a.C.), quien en su Historia ${ }^{2}$ ofrece una diversidad de datos acerca de la India y de sus moradores.

Las gentes que habitan el subcontinente, según Heródoto (III, 94,2) es la más numerosa de la tierra:

«Y por cierto que, de todos los pueblos que conocemos, el número de los indios es, con mucho, el más elevado; por eso satisfacian un tributo equivalente al de todos los demás juntos: trescientos sesenta talentos de oro en polvo. Ésta era la vigésima provincia».

\footnotetext{
1 «Oriente comprende lo que no es el Occidente judío-griego, o sea, el mundo islámico (Norte de África y Próximo Oriente) y el resto de Asia». J.R. RIVIĖRE, Oriente y Occidente, Salvat, Barcelona, 1979, págs. 55-56.

2 Su obra, dividida en nueve libros, constituye la fuente principal para el estudio de las guerras médicas y de las poblaciones mezcladas en ellas.
} 
Y más adelante Heródoto (III, 98,2) sigue diciendo:

«Por cierto que los indios consiguen esa gran cantidad de oro, que les permite hacer llegar al rey el oro en polvo que he mencionado, del siguiente modo. La zona oriental de la India es un arsenal (de hecho, de los pueblos que conocemos y sobre los que constan noticias fidedignas, los indios son los que, en Asia, residen más hacia el lejano oriente); pues bien, la arena hace que la zona que se extiende al este de los indios sea un desierto".

Al referirse a los usos y costumbres de los habitantes de la India, Heródoto (III, 98, 2-4) señala lo siguiente:

«Entre los indios, por otra parte, hay numerosos pueblos, pero entre sí no hablan una misma lengua; además, unos son nómadas, mientras que otros no; y algunos residen en las zonas pantanosas del río y se alimentan de peces crudos que capturan a bordo de embarcaciones con cañas (cada embarcación, por cierto, la hacen con un solo cañuto de caña). Estos indios, además, llevan una vestimenta confeccionada con juncos: después de recoger el junco del río y de machacarse, lo trenzan convenientemente a modo de una estera $y$, luego, se lo ponen como un peto".

Y a continuación Heródoto (III, 99,2) afirma:

"Otros indios, que habitan al este de estos últimos, son nómadas, comen carne cruda y se llaman padeos. $Y$, según dicen poseen las siguientes costumbres: cuando un miembro de la tribu - sea hombre o mujer-enferma, si se trata de un hombre, los hombres allegados a él lo matan, alegando que, si dicho sujeto acaba siendo consumido por la enfermedad, sus carnes se les echan a perder. $Y$ aunque niegue estar enfermo, ellos, sin darle crédito, acaban con él y luego se dan un banquete a su costa. Igualmente, si es una mujer quien enferma, las mujeres más estrechamente ligadas a ella hacen lo mismo que los hombres. Pues el caso es que, a quien llega a la vejez, lo inmolan y luego se dan un banquete a su costa. Pero entre ellos no son muchos los que llegan a la condición de tal, dado que previamente matan a todo el que cae enfermo".

En lo que se refiere a las costumbres ascéticas de algunos indios, Heródoto (III, 100) narra lo siguiente:

"Y hay otros indios que observan un régimen de vida distinto; se trata del siguiente: no matan a ningún ser vivo, no siembran nada, y no acostumbran a tener casas; simplemente se alimentan de hierbas y disponen de cierta legumbre -aproximadamente del tamaño de un grano de mijo-provista de una vaina, que surge de la tierra en estado silvestre; esas gentes recogen dicha legumbre, la cuecen con vaina y todo $y$, luego, se la comen. $Y$ si uno de ellos cae enfermo, se va a un despoblado y se tiende en el suelo, sin que nadie, ni a su muerte ni durante su enfermedad, se cuide de él». 
Sobre las costumbres sexuales de los indios, Heródoto (III, 101, 2) comenta:

«Todos estos indios de los que he hablado se aparean en público, exactamente igual que las reses; y todos tienen la piel del mismo color, un color semejante al de los etíopes. Asimismo, el semen que estos individuos eyaculan al unirse a las mujeres no es blanco como el de los demás humanos, sino negro, como el color de su piel».

La información que nos ofrece el gran historiador griego en su Historia sobre algunos aspectos de la India y de sus moradores, parece apoyarse en los escritos de Esquilax de Carianda ${ }^{3}$ (siglo vı a.C.), griego famoso encargado de guiar las naves de Darío a lo largo del Indo, y en el historiador y geógrafo griego, Hecateo de Mileto ${ }^{4}$ (siglo vI a.C.). Se describen en estas narraciones las maravillas de la India, su fauna original, su flora sorprendente, con detalles pintorescos sobre las costumbres de sus habitantes. Estas fragmentarias descripciones son luego exageradas hasta lo inverosímil por Ctesias de Cnido ${ }^{5}$ (siglo v a.C.), que vivió veinte años en la corte persa, en calidad de médico, reflejando, sin duda, en sus escritos las impresiones de los áulicos.

Aunque no son muy numerosas, existen referencias de los dramaturgos griegos a la India. Esquilo (circa 525-456 a.C.), contemporáneo de Esquilax, Hecateo y Heródoto, alude a los indios en una de sus tragedias, Las suplicantes (284-290):

"Sé que hay indias nómadas, vecinas de la gente de Etiopía, que recorren la tierra montadas en camellos ensillados, cual si a caballo fueran. También os hubiera confundido, si armadas de arcos estuvierais, con esas Amazonas que tienen por costumbre el vivir sin marido y comer carne cruda».

\footnotetext{
3 «Navegó desde Kaspápyros y desde el país de Paktyké, por el río Indo hacia el mar, y luego, siguiendo la costa del Mar Arábigo, entró en el Mar Rojo llegando a Suez, después de 30 meses de navegación. Esta información acerca de la ruta seguida por Esquilax y la duración de su viaje es proporcionada por Herodoto, Historiae IV, 44. La expedición de Esquilax tuvo lugar probablamente entre el 519 y el 512 a.C. Esquilax fue el primer griego que visitó la India y que conectó India y Egipto por vía marítima. Lamentablemente los libros escritos por Esquilax no nos han llegado. Si conocemos algo acerca del contenido de dichos libros, es sólo por unos pocos fragmentos, citas o referencias encontrados en trabajos de otros autores. Fueron utilizados, entre otros, por Hecaleo, Herodoto, Aristóteles, al referirse a la India». F. Tola y C. DragonetTI, «India y Grecia antes de Alejandro" en Boletín de la Asociación Española de Orientalistas, Año XXXIV, 1998, págs. 353-354.

4 «Escribió una obra geográfica: Períodos Gês. Dependía para su descripción de la India de la información suministrada por Esquilax, porque él no había visitado la India. Su obra se ha perdido; sólo quedan fragmentos». Ibŕd., pág. 357.

5 «A pesar de sus deficiencias Ctesias fue muy leído y citado por los autores que lo seguían; puede considerársele como la principal fuente para el conocimiento de la India antes de la expedición de Alejandro y una de las principales después de ella». Ibíd., pág. 366.
} 
También Sófocles (circa 494-406 a.C.) se refiere a la India, en una de sus grandes tragedias, Antígona (1038-1039): «Lucraros, comprad el electro de Sardes, si queréis, y el oro de la India».

Los testimonios de que Pitágoras ${ }^{6}$, Demócrito 7 , Licurgo, Aristóteles y Fedón viajaron a la India y recibieron enseñanzas de grandes maestros son sin duda de valor dudoso ${ }^{8}$.

Asimismo resultan dudosas las noticias de que Platón inició los preparativos para llevar a cabo un viaje a la India, pero tuvo que renunciar por las condiciones de guerra ${ }^{9}$. Resultan igualmente cuestionables las noticias de Eusebio, padre de la Iglesia, según las cuales el músico griego Aristoxeno de Tarento aseguraba que:

"An Indian visited Socrates, the philosopher par excellence, in Athens, and asked him about the meaning of his philosophizing. When Socrates replied that he was studying problems of human life, the Indian laughed and explained

6 Según H.P. BLAVATSKy, el filósofo griego Pitágoras: «viajó por todo el mundo y entresacó su filosofía de los diversos sistemas de que tuvo conocimiento. Así, estudió las ciencias esotéricas con los bracmanes de la India». H.P. BLAVATSKY, Glosario teosófico, Kier, Buenos Aires, 1982. PAUL BRUNTON afirma que: «Pitágoras viajó hasta la India y consiguió obtener la iniciación en la sabiduría secreta de los bracmanes, dividió a los hombres en tres clases, ubicando a los que amaban la filosofía en la más elevada. Por cierto que en relación con eso acuñó y empleó la palabra filosofía y fue así el primer europeo en hacerlo". P. Brunton, Más allá del yoga, Kier, Buenos Aires, 1975, pág. 96. Para GLASENAPP: «De ningún filósofo griego se ha afirmado tan frecuentemente y tan pronto que fuera influido por la sabiduría india como de Pitágoras que floreció alrededor del 530 a.C. Después que Onesicrito llamó la atención sobre las coincidencias entre su doctrina y la de los indios, Alejandro Polihistor (alrededor de 70 a.C.) afirmó por primera vez que Pitágoras aprendió todo de los brahmanes. La misma información la transmiten Apuleyo (150 d.C.) y Filostrato (alrededor de 200 d.C.). Después que se descubrió la vía marítima hacia el Este muchos investigadores afirmaron la dependencia de Pitágoras de las ideas indias [...] Se ha visto la base principal para esta afirmación en el hecho de que Pitágoras habría sido el primero en Grecia en enseñar la transmigración de las aimas [...] El otro argumento, que se aduce en favor de la tesis de la toma en préstamo por parte de Pitágoras, se refiere a los trabajos matemáticos de Pitágoras». H. vON GLASENAPP, La filosofía de los hindúes, Barral, Barcelona, 1977, págs. $450-451$.

"Greek physiologers like Anaximander, Democritus, Empedocles, and Epicurus were influenced by the Sâmkhya philosophy. The doctrine of Empedocles that nothing can arise which has not existed before, and that nothing existing can be annihilated, finds its exact parallel in the Sâmkhya doctrine about the eternity and indestructibility of matter. Greek tradition records that Thales, Empedocles, Anaxagoras, Democritus, and others undertook journeys to oriental countries in order to study philosophy. In view of the antiquity of India's contact with Greece and the Greek tradition referred to earlier, it seems fairly certain that Greek philosophy is derived from India philosophy". The cultural heritage of India, The Ramakrishna Mission. Institute of Culture, Calcutta, 1993, pág. 154.

8 «En conexión con la afirmación de que una serie de doctrinas griegas surgieron en dependencia de doctrinas indias, se discutió ya en la antigüedad el problema de si la India o Grecia era la patria originaria de la filosofía». H. vON GLASENAPP, ob.cit., pág. 453.

o Ibíd., pág. 19. 
that it was impossible to study and understand human thing without considering the divine ${ }^{10}$.

\section{ALEJANDRO MAGNO EN LA INDIA}

Está fuera de toda duda razonable que estudiosos griegos mantuvieron contactos con pensadores hindúes ${ }^{11}$ con ocasión de la campaña de Alejandro Magno ${ }^{12}$ (356-323 a.C.) (figura 1). Cuando éste atravesó la India del norte, oyó hablar en Taxila ${ }^{13}$ de los sabios hindúes que tenían

10 W. Halbfass, India and Europe, State University of New Vork Press, Albany, 1988, pág. 8.

11 «Desde la conquista de la India por Alejandro Magno, hasta el siglo $v$ de nuestra era, se pueden contabilizar más de un centenar de referencias a los brahmanes. Éstas fueron efectuadas por autores griegos y latinos como Jares, Nearco, Onesícrito, Cleitarco, Aritóbulo, Clearco, Aristoxeno, Megasthenes, Cicerón, Alejandro Polyhistor, Diodoro, Aristócrates, Nicolás Damasceno, Estrabón, Valerio Máximo, Filón de Alejandría, Quinto Curcio, Lucano, Flavio Josefo, Dion Cirsóstomo, Plutarco, Apiano, Arriano, Claudio Ptolomeo, Luciano, Apuleyo, Tertuliano, Clemente de Alejandría, Filóstrato, Bardesanes, Diógenes Laercio, Dion Cassio, Aeliano, Hipólito, Orígenes, Solino, Porfirio, Eusebio, Amiano Marcelino, Epifanio, Prudencio, Juan Crisóstomo, Jerónimo, San Agustín, Palladio». R. C. Vofchuk, «Primeras menciones del Budismo en el mundo greco-romano» en Revista de Estudios Budistas, Año I, Núm. 2, México (Octubre, 1991-Marzo, 1992), pág. 117.

12 «Después de la muerte de Dario, Alejandro se había proclamado heredero universal del Imperio persa. La satrapia india debía formar parte de esta herencia. En el año 327, pese a la abierta oposición de sus soldados, se dispuso a tomar posesión de este legado; especialmente apetitoso para Alejándro, pues la India representaba, en la opínión griega, el país misterioso, opulento, exótico. Dos años de intensa actividad fueron necesarios para someter y organizar las regiones del valle del Indo. La lucha se hace alli muy difícil por el clima, las condiciones del terreno pantonoso y lleno de ríos, no menos que por la infinita masa humana que le opone el rey Poros. Al fin, y con la ayuda del príncipe local Taxiles, vence en la batalla de Hysdaspes, y en otros memorables enfrentamientos. Pero alí por los combates y las enfermedades tiene cuantiosas bajas y decide dejar una guarnición en las tierras conquistadas bajo las órdenes de Eudemos en el sur. A su vez, deja otros territorios del norte en calidad de soberanos feudatarios con los reyes nativos Abisares, Taxiles y su antiguo enemigo Poros.

De momento, Alejandro hubo de renunciar a conquistar el resto del país, porque sus tropas se negaron en absoluto a dar un paso adelante sobre tierras enteramente desconocidas. Las nuevas provincias, dos satrapias (Pendjab-Sind) fundadas por Alejandro iban a tener una vida efímera: sólo ocho años. Pero antes de partir fundó en el delta el puerto de Pattala e inició su vuelta por tres rutas: Nearco por mar, Crátero por el interior, Alejandro por la costa. A partir de este momento la influencia griega - unas veces por razón de vecindad, otras por el dominio directo sobre diversas zonas del noroeste - iba a ser decisiva. Se produjo así el más fuerte impacto exterior que la India hubiera sufrido a lo largo de toda su historia: incrementado luego por los partos, escitas, y yuetche, quienes, más o menos helenizados, iban a suceder a los griegos en la Bactriana». VV.AA., Manual de Historia Universal, Antiguo. Oriente, Nájera, Vol. II, Madrid, 1983, págs. 486-487.

13 Situada a 32 kilómetros al oeste de Rawalpindi, en el Punjab, fue un gran centro de saber. Era célebre por su universidad, en la que enseñaban las artes y las ciencias de la época. Durante el gobierno del monarca del ímperio Maurya, Ashoka que vivió en el siglo ılı a.C., Taxila alcanzó una posición de primer orden entre las ciudades del noroeste. Ver Syed Ashfaq Naqvi, «Taxila, gran centro en el Oriente" en Revista de Estudios Budistas, Núm. 8 (Octubre 1994 a Marzo 1995). 
fuerzas suprahumanas y poderes paranormales; envió a Onesícrito ${ }^{14}$, filósofo e historiador griego, discípulo de Diógenes, para investigarlos.

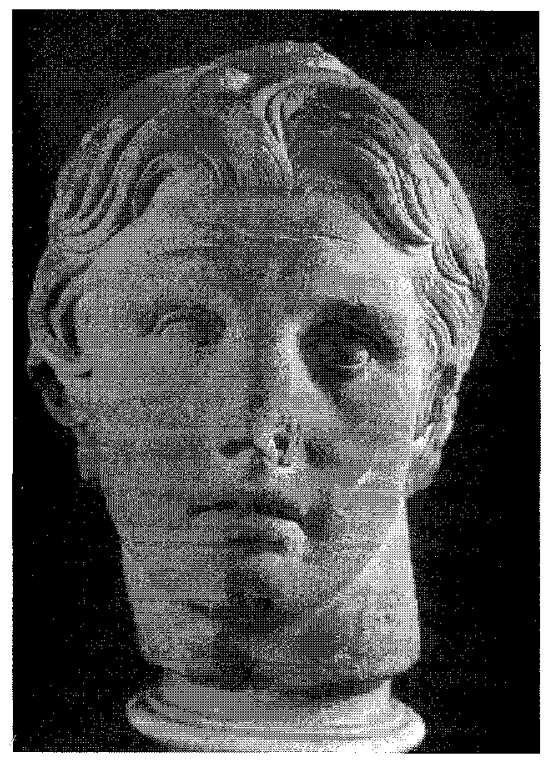

Fig. 1. Alejandro Magno.

Estrabón, el gran geógrafo griego, narra en su obra el encuentro de Onesícrito con quince ascetas desnudos en distintas posturas e inmnóviles, soportando el sofocante calor de la India:

"He found fifteen men at a distance of twenty stadia from the city, who where in different postures, standing or sitting or lying naked and motionless till evening, and that they returned to the city; and that it was very hard to endure the sun, which was so hot that at midday no one else could easily endure walking on the ground with bare feet» ${ }^{15}$.

14 Todos los acontecimientos acaecidos durante la expedición a la India de Alejandro fueron registrados con todo detalle por Nearco, Onesícrito, Aristóbulo y Ptolomeo. Y aunque se han perdido en su totalidad, actualmente se conocen debido a las transcripciones y referencias, entre otros de Estrabón, Arriano y Diodoro de Sicilia.

15 Strabo, Geography XV.I. 63. 
Y más adelante, se refiere a la conversación entre Onesícrito y el asceta indio Kalanos ${ }^{16}$, a quien se dirige en cumplimiento de su misión, esto es, informarse acerca de sus enseñanzas para luego transmitírselas a Alejandro ${ }^{17}$. Los aspectos que más Ilamaron la atención de Onesícrito fueron: su postura ante la muerte, las costumbres ascéticas, la resistencia física, la firmeza, la actitud contemplativa y la desnudez, característica que llevó a los griegos a llamarlos «gimnosofistas" ${ }^{18}$.

En la comitiva de Alejandro se hallaban también Anaxarco, seguidor de las teorías de Demócrito ${ }^{19}$, y su amigo Pirrón de Elis. Según el escritor griego, Diógenes Laercio:

«Pirrón habría llevado una vida solitaria. Se habría quedado impresionado al oír a un hindú denostar a Anaxarjos, porque éste, en lugar de mejorar a otros con la enseñanza, servía en la corte del rey. En vista de que Pirrón también realizaba en la vida práctica su abstención escéptica, al señalar como meta del sabio la indiferencia frente a la existencia y la serenidad de ánimo, se ha pensado muchas veces que han debido ser decisivas para la elaboración de su doctrina influencias recibidas por él en la India» 20.

No podemos afirmar que la aventura de Alejandro Magno ejerciera una influencia decisiva sobre los destinos del subcontinente, pero sí tuvo una gran importancia:

«Los ocho años de ocupación macedónica abren una era de varios siglos, durante los cuales, el helenismo no sólo será un factor de cultura, sino de go-

16 "La muerte voluntaria de este asceta indio, devorado por las llamas sin el menor gesto de dolor, ante el estupor de todo el ejército griego, es quizá uno de los episodios más significativos de esta campaña en cuanto a enfrentamientos de valores distintos otorgados por griegos y por indios a nociones esenciales: vida y muerte». R.C. VOFCHUK, «Las costumbres y creencias filosófico-religiosas de la India según las Informaciones de Nearco de Cretas en Boletín de la Asociación Española de Orientalistas, Año XVIII, 1982, pág. 279.

17 "La figura de Onesícrito aparece generalmente asociada a la de quien fuera considerado, con justicia, el iniciador de una nueva etapa en la historia de la humanidad, Alejandro Magno". R.C. VOFCHUK, “Los informes de Onesícrito. Cronista de Alejandro Magno sobre la India». Boletín de la Asociación Española de Orientalistas, Año XXII, 1986, pág. 187.

is D. LaERCIO, Vidas de los más ilustres filósofos griegos, Orbis, vol. 1, Barcelona, 1986, pág. 21.

19 «Diógenes Laercio (fines del siglo « d.C.) en Vidas de los filósofos eminentes IX, 34 (=Diels II, 68, A.I) nos informa que Demócrito, de acuerdo con Demetrio de Magnesia (siglo I a.C.) y con Antístines de Rodas (siglo II a.C.), visitó Caldea, Persia y ef Mar Rojo, y que, según algunos autores, se encontró con los filósofos desnudos (=gymnosophistaí, ascetas) en India, y llegó a Etiopía [...] Ahora bien no es posible aceptar, en vista de la evidencia con que contamos en la actualidad, que Demócrito haya viajado a la India. El testimonio de Diógenes Laercio es muy vago (Algunos dicen que...), Clemente de Alejandría, que habla de los viajes de Demócrito, citando incluso un pasaje que se le atribuye, no dice nada de su visita a la India». F. TOLA y C. DRAGONETTI, ob.cit., págs. 363 y 364 .

20 Citado en H. von Glasenapp, ob.cit, pág. 20. 
bierno en los confines del oeste de la indianidad. Se estableció un contacto directo entre las civilizaciones mediterráneas y las del Penyab, asi como del Asia Central, la Babilonia semítica y el Imperio persa ya no son una pantalla entre el Occidente y el Oriente. Son estos hechos de inmenso alcance no sólo para la historia griega o de la India, sino para la universal, la única verdadera Historia» ${ }^{21}$.

\section{ENCUENTROS ENTRE LA INDIA Y OCCIDENTE DESPUÉS DE ALEJANDRO MAGNO}

La autorizada relación de Megástenes (s. III a.C.) ${ }^{22}$, historiador y geógrafo griego, embajador del rey Seleuco Nicátor en la corte del primer monarca maurya, Chandragupta (302-291 a.C.), en Patna (antigua Pataliputra), después de haber tomado parte en la expedición de Alejandro ${ }^{23}$, nos proporciona, si bien en forma fragmentaria, abundantes y muy precisas noticias acerca de las doctrinas hindúes sobre la inmortalidad del alma, comparándolas con las enseñanzas de Platón, y de sus creencias en Dionisio (Shiva) y en Hércules (Krishna); y datos estimables sobre la organización de la sociedad índica, como el régimen de castas, denominado por Megástenes «fracciones", en las que se encuentran confinados los individuos y separados mutuamente por infranqueables barreras. Documentos valiosos, fuente de todos los conocimientos en torno a la India en la Antigüedad y en la Edad Media ${ }^{24}$.

Llama la atención el hecho de que las grandes misiones búdicas (figura 2) de Ashoka ${ }^{25}$ (268-240 a.C.), monarca del imperio maurya, en el norte de la India, pasaran sin dejar mucha huella. De hecho, el nombre de Ashoka ${ }^{26}$ —el más grandioso de los antiguos monarcas de la India- cayó en el olvi-

21 VV.AA., La India antigua y su civilización, Uteha, México, 1957, pág. 30.

22 Ver H. de Lubac, La rencontre du bouddhisme et de l'Occident, Aubier, Paris, 1952, pág. 10.

23 «No se conocen con exactitud los motivos que llevaron a Alejandro el Grande a efectuar la larga y difícil campaña de la India. Tal vez uno de ellos haya sido que el hijo de Filipo, como sucesor de los Aqueménidas, se sentía obligado a recupar territorios indios que habían pertenecido al reino de los persas bajo el gobierno de Darío I. Por otro lado, la idea de que existía una civilización fascinante por lo exótica, por sus tesoros, por su poderío, obró seguramente de manera decisiva sobre el ávido temperamento del gran macedonio». R.C. VOFCHUK, "Las costumbres y creencias filosófico-religiosas de la India según las Informaciones de Nearco de Creta", pág. 277.

24 Relató sus observaciones sobre el subcontinente en sus Indika, en las que Estrabón, Arriano y Diodoro hallaron una fuente importante de inspiración. Gracias a Megástenes se posee una información valiosa sobre los pueblos y la sociedad india en la período Maurya.

25 Ver F. TOla y C. DRAgonett, «Un gran emperador budista, Ashoka» en Revista de Estudios Budistas, Año II, Número 3 (abril 1992 a septiembre 1992).

26 Las fuentes para la biografía de Ashoka son, por una parte, las crónicas pâli, donde se lo presenta como un rey budista; por otra, los documentos arqueológicos, ante todo los Edictos de Ashoka, grabados en piedra y columnas. Ver F. Rodríguez Adrados (tr.), Asoka, Edictos de la Ley Sagrada, Edhasa, Barcelona, 1987. 


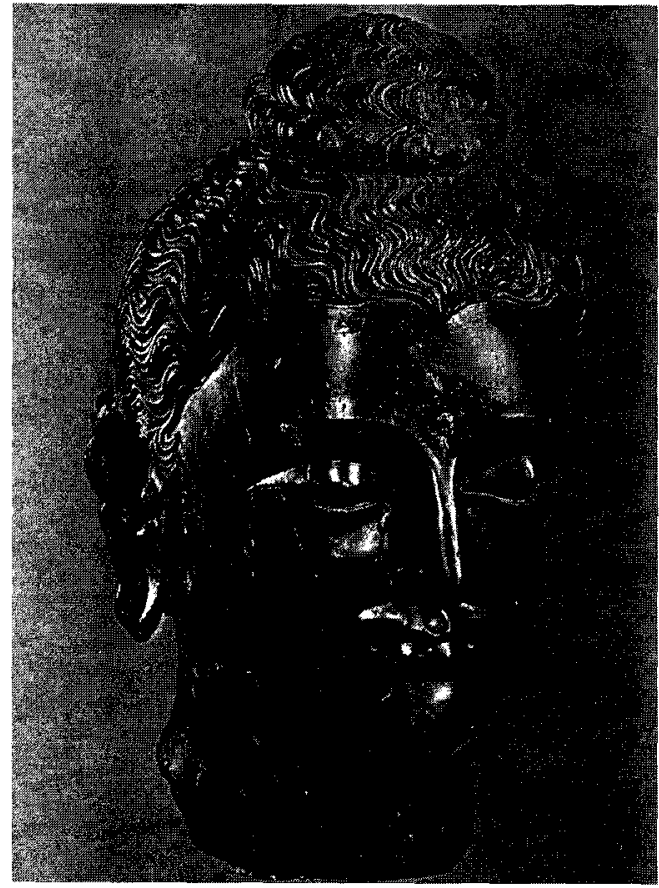

Fig. 2. Cabeza del Buda (Museo Nacional de Copenhague).

do hasta que en el siglo XIX se lo recuperó, cuando se descifraron sus inscripciones, talladas en piedras y en columnas.

Hasta hace aproximadamente cien años, Ashoka sólo era uno de los muchos reyes mencionados en la lista dinástica mauryana incluida en los Purana. Pero en 1837 el orientalista James Prinsep descifró una inscripción hecha en la más antigua escritura india conocida. Esta inscripción se refería a un rey llamado Devanampiya Piyadasi. Poco a poco se unieron los distintos indicios y parecieron adquirir sentido, pero la confirmación final llegó en 1915, al descubrirse otra inscripción en la cual el autor se llama a sí mismo rey Ashoka, Piyadassi. Se hizo patente que Piyadassi era un segundo nombre de Ashoka ${ }^{27}$.

27 «Ashoka (272-232 a.C.) es uno de los muchos epítetos que se ganó el rey Mauryana Vardhana, el emperador más famoso de toda la historia de India. Ashoka significa sin dolor, pues nació sin herir a su madre; también se llama Piyadasi o amable mirada, y Devanampiya o amado por los dioses". C. Gaficía-OrmaeCHEA, "India inmortal», Historias del Viejo Mundo en Historia 16 , n. ${ }^{\circ}$ 18, Madrid, 1994, pág. 80. 
Los edictos y las inscripciones de Ashoka ubicados en varias partes de su imperio nos familiarizan no solamente con la personalidad del rey, sino también con los acontecimientos de su reinado. Acaso el más conocido de ellos sea su conversión al budismo. Ésta se efectuó después de la famosa campaña de Kalinga (actual provincia de Orissa).

"Ocho años después de su coronación, el rey, amado de los dioses, el de la benévola mirada, sitió Kalinga. 150.000 hombres quedaron allí cautivos, 100.000 fueron pasados a cuchillo, y un número aún mayor perdió la vida. Pero luego, habiendo sido conquistada Kalinga, el amado de los dioses se transformó para seguir más estrictamente la recta conducta, para amar la recta conducta y para adquirir sabiduría en la recta conducta. Ésta fue la promesa del amado de los dioses en el asedio de Kalinga. Tales son las palabras iniciales de una inscripción grabada en la roca en Shahbazgarhi [...] Nunca jamá - sigue diciendo la citada inscripción, como otras muchas semejantes- ni él ni sus sucesores emprenderán una guerra de conquista, que siembre el país de dolor y lágrimas y rompa los lazos de hermandad entre los hombres» ${ }^{28}$.

La destrucción causada por la guerra llenó al rey de remordimientos. En un esfuerzo por buscar la expiación se convirtió en un celoso devoto del budismo; y para predicar al pueblo la nueva moral de la tolerancia hizo grabar sus edictos en altos pilares de piedra distribuidos por todo el imperio. De entre los que se han conservado hasta hoy, es particularmente famoso el de Sarnath, coronado por un capitel con cuatro leones sobre una «Rueda de la Ley» (figura 3), esculpido en brillante piedra. Este capitel se ha convertido en el emblema de la unidad y autonomía de la India actual.

Ashoka se vanaglorió en sus inscripciones en columnas y rocas de haber enviado embajadores del budismo a los reinos vecinos de los cholas y de los pandyas en el sur de la India, a otros países como Birmania y Ceilán e incluso a los dominios de Antíoco II, rey de Siria, de Ptolomeo II Filadelfo, rey de Egipto, de Magas, rey de Cirene, de Antígono, rey de Macedonia, y de Alejandro, rey de Epiro, contemporáneos todos ellos de Ashoka y mencionados por él en su Edicto XIII ${ }^{29}$.

A comienzos del siglo $\|$ a. de $C$., príncipes indogriegos se asentaron en la Bactriana y no cesaron de llevar a cabo incursiones en el valle del Indo: uno de ellos, a quien los griegos llamaban Menandro y los indios Milinda, que reinó alrededor del año 150 a.C. en los territorios del noroeste de la

28 H. Boekhoff y F. Winzer (dirs.), Historia de la cultura oriental, Labor, Barcelona, 1968, pág. 229.

29 Ver F. Rodriguez Adrados (tr.), ob.cit., pág. 102. 




Fig. 3. Capitel de los Leones, de la época del rey Ashoka (Museo de Sarnath).

India, alcanzó gran celebridad en la historia del budismo primitivo, porque figura como principal protagonista de la obra escrita en pâli ${ }^{30}$, Las preguntas de Milinda ${ }^{31}$, la obra no canónica más importante del budismo theravâda, compuesta en forma de un diálogo entre el monje budista Nâgasena y el rey Menandro.

Con el Imperio romano, se hicieron aún más frecuentes los intercambios por tierra y por mar con el mundo oriental, por lo que aumentó la importancia de los centros comerciales, desde Alejandría; Roma envió regularmente legaciones a la India, para estudiar filosofía y ciencia, y se

30 Dialecto indio, derivado del sánscrito, en el que están redactados los textos canónicos del budismo theravâda.

31 Este texto parece haber sido utilizado como obra de propaganda para la conversión de los griegos del noroeste de la India, poco antes de la era cristiana. Su contenido gira en torno a las doctrinas nucleares del budismo, especialmente la del no-yo, la ley de la causalidad y la de la reencarnación. 
tiene noticia de diversas embajadas indias en la corte de Trajano (siglo I) y en la de Claudio. También se tiene información de la llegada a Roma de misioneros budistas en la época del emperador Ashoka.

En la época de Augusto (figura 4) (63 a.C.-14 d.C.) fue a Roma una embajada india; en ella iba el asceta, Zarmanochegas, "que puso término a su vida en Atenas, haciéndose quemar vivo" ${ }^{32}$. Nos habla Cicerón (Tusculanae, $V$, 78) del holocausto de la viuda desolada en la pira del esposo amado; Plinio, Apuleyo y Julio Valerio, se admiran de las rigurosas ascesis de los filósofos brahmanes, denominados por el pueblo heleno "gimnosofistas".

Plotino ${ }^{33}$ (204-270), máximo representante del neoplatonismo, acompañó a Gordiano III en la expedición contra los persas, movido por el

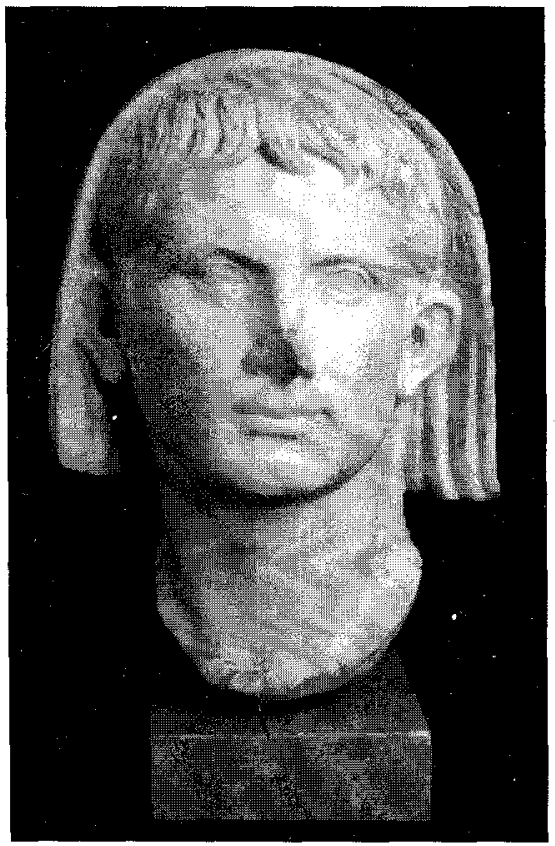

Fig. 4. Augusto.

32 J.R. Rivière, El pensamiento filosófico de Asia, Gredos, Madrid, 1960, pág. 20.

33 «Podríamos referirnos a la opinión de Bidez y de Bréhier sobre las analogías entre Platón y Plotino, por una parte, y ciertas doctrinas orientales, por otra". G. Tuccl, Historia de la filosofía hindú, Luis Miracle, Barcelona, 1974, pág. 11. 
deseo de aprender directamente de los maestros orientales las doctrinas religiosas y filosóficas de la India ${ }^{34}$ y del Irán, en las cuales se habia inspirado ya, a través de las informaciones recogidas de una legación india ante Antonino Pío, Bardesanes, cuya doctrina de tipo gnóstico, es poco conocida.

Durante varios siglos, Occidente sabrá muy poco más acerca de las regiones de Asia. Los hombres de la Edad Media no se sienten atraídos por el exotismo: Roma es para ellos el centro del mundo. Por otra parte, la teología cristiana pretendía poseer la verdad, de ahí su falta de interés por el pensamiento indio.

\section{BIBLIOGRAFIA}

Ashfaq Naqvi, S.: "Taxila, gran centro en el Oriente" en Revista de Estudios Budistas, N. 8 (Octubre 1994 a Marzo 1995), págs. 64-76.

BLAVATSKY, H.P.: Glosario teosófico, Kier, Buenos Aires, 1982.

BOEKHOFF, H. y WINZER, F. (dirs.): Historia de la cultura oriental, Labor, Barcelona, 1968.

Brunton, P.: Más allá del yoga, Kier, Buenos Aires, 1975.

ESQUiLO: Tragedias, Gredos, Madrid, 1986.

Garcia-Ormaechea, C.: "India inmortal", Historias del Viejo Mundo en Historia 16, n. 18 , Madrid, 1994.

GLASENAPP, H.: La filosofía de los hindúes, Barral, Barcelona, 1977.

HALBFASS, W.: India and Europe, State University of New York, 1998.

Heródoto: Historia, Gredos, Libros III-IV, Madrid, 1986.

JONES, H.L. (tr.): The Geography of Strabo, VII, William Heinemann, Books, XV-XVI, London, 1903.

LAERCIO, D.: Vidas de los más ilustres filósofos griegos, Orbis, Vol. I, Barcelona, 1985.

LuBAC, H. de: La rencontre du Bouddhisme et de L'Occident, Aubier, Paris, 1952.

Riviere, J.R.: El pensamiento filosófico de Asia, Gredos, Madrid, 1960.

- Oriente y Occidente, Salvat, Barcelona, 1980.

Rodríguez Adrados, F. (tr.): Asoka, edictos de la Ley Sagrada, Edhasa, Barcelona, 1987.

ROMÁN, M.T.: «Oriente en Occidente», A Distancia, UNED, Madrid, 1996, págs. 93-97.

SófOCLES: Tragedias, Alianza, Madrid, 1988.

34 «Se acepta que gnósticos como Basilides, neoplatónicos como Plotino y Porfirio y teólogos cristianos como Orígenes utilizaron pensamientos indios en la construcción de sus doctrinas. Se han señalado como ideas que pueden derivar de la India las siguientes: la teoría de la unidad de todo, la teoría de las emanaciones, la idea acerca de múltiples mundos celestiales, la división del hombre en tres clases que corresponden a los tres gunas del Sânkhya, las enseñanzas sobre contemplación y éxtasis y los poderes sobrenaturales que con ellos se obtiene asi como naturalmente las concepciones acerca del dolor universal, preexistencia, transmigración y liberación. También la utilización de la comparación del ciego y del cojo para señalar la relación del cuerpo y del alma puede remontarse a modelos indios y la afirmación de Plotino que él no necesitaba ir donde los dioses sino que los dioses debían venir a él [...] También se han querido encontrar influencias indias en Aristóteles". H. VON GLASENAPP, ob.cit., pág. 448. 
Tola, F. y DragonetTI, C.: «India y Grecia antes de Alejandro» en Boletín de la Asociación Española de Orientalistas, Año XXXIV, 1998, págs. 353-377.

- «Un gran emperador budista: Ashoka» en Revista de Estudios Budistas, Año II, Número 3 (abril 1992 a septiembre 1992), págs. 97-116.

AA.VV.: The cultural heritage of India: The Ramakrishna Mission. Institute of Culture, Vol. I, Calcuta, 1993.

TucCl, G.: Historia de la filosofía hindú, Luis Miracle, Barcelona, 1974.

VOFCHUK, R.C.: «Las costumbres y creencias filosófico-religiosas de la India según las Informaciones de Nearco de Creta" en Boletín de la Asociación Española de Orientalistas, Año XVIII, 1982, págs. 277-293.

- "Los informes de Onesícrito. Cronista de Alejandro Magno sobre la India» en Boletín de la Asociación Española de Orientalistas, Año XXII, 1986, págs. 187-202.

- "Primeras menciones del Budismo en el mundo grecorromano", en Revista de Estudios Budistas, Año I, Núm. 2, México (octubre, 1991-marzo, 1992), págs. 117-137.

VV.AA.: La India antigua y su civilización, UTEHA, México, 1957.

VV.AA.: Manual de Historia Universal, Antiguo Oriente, Nájera, Vol. II, Madrid, 1983. 